\title{
Emerging Spanning Trees in the Work of Candilis-Josic-Woods
}

\section{Georgios-Spyridon Athanasopoulos ${ }^{1}$}

Published online: 17 August 2020

(C) The Author(s) 2020

\begin{abstract}
This paper introduces the use of graph theory for the study of the work of CandilisJosic-Woods. A short introduction to the architects' main strategies as members of Team X and CIAM (Congrès Internationaux d'Architecture Moderne) critics is given. Geometry and computational design methods for city planning and design are briefly discussed. Definitions of the minimum spanning tree, the shortest walk tree and the Steiner tree are then developed. The research projects these methods onto the main principles of Candilis-Josic-Woods' planning and urban design approach to reinforce their strategic concepts. Distance-related and proximity-based ideas and their importance are sought in the literature related to Candilis-Josic-Woods' body of work. Algorithmic based examples approximating a Euclidean Steiner tree are shown and discussed in the context of Candilis-Josic-Woods' syntax. This paper argues that the generation of additional points through the use of a Euclidean Steiner tree algorithmic process is of importance in the work of Candilis-Josic-Woods as it allows for a systematic but emerging creation of hubs that can be activated as space on the one hand, and facilitate pedestrian circulation on the other. The project seeks to demonstrate the relevance of the triplet's design methods to today's complex networks of urban environments.
\end{abstract}

Keywords Candilis-Josic-Woods · Team X · Urban design · Geometry · Patterns · Algorithms · Graph theory · Minimum spanning tree $\cdot$ Euclidean Steiner tree · Steiner points

Georgios-Spyridon Athanasopoulos gsa26@cam.ac.uk

1 Department of Engineering, Gonville and Caius College, University of Cambridge, Trinity Street, Cambridge CB2 1TA, UK 


\section{Introduction}

In a post-war setting of reconstruction across the world, CIAM (Congrès Internationaux d'Architecture Moderne) offered a unique place for fertile discussions to promote new ideas about the city and the built environment. As the modern movement had difficulties convincing the world that it could maintain its pre-war radical ideas in a cold war atmosphere (Frampton and Simone 2015: 14), an emerging critique to CIAM's main protagonists from a younger generation of architects aspired to shift the discussion of urban design from the individual city occupant to the collective group of residents (Mumford 2009: 31). Along these lines, the 10th CIAM allowed for the introduction of anthropological structuralism in the planning discussion through Aldo van Eyck (Frampton and Simone 2015: 16), as well as for the formation of a new group of CIAM members known as Team X (Avermaete 2005: 18-20). A complete chronology of Team $\mathrm{X}$ meetings is reported by Mark Risselada and Dirk van den Heuvel (2005) and Smithson (1991) and the chronicles of CIAM are documented by Mumford (2000).

A sub-group of Team X intellectuals were Georges Candilis, Alexis Josic and Shadrach Woods, a well-known triplet who actively engaged with urban design through the development of projects globally and contributed heavily to the architecture and urbanism discourse. A key idea shared among the Candilis-Josic-Woods group-including Alison and Peter Smithson, Aldo van Eyck and Jacob Bakema-was the notion of the "architect-planner", an agent with the role to balance and advocate the contributing bodies' concerns and ideas throughout the planning process (Mumford 2009:16). The work of this group, including the network studies of Candilis-Josic-Woods, was later characterized by Anthony Vidler as an attempt to "functionalize form in the name of humanism" (Vidler 2004: 29).

Within the context of today's urban planning and design disciplines seeking to abstract tools and strategies from across sciences (Busquets and Correa 2006: 14), this paper explores fundamental concepts from the fields of graph theory and computational geometry to introduce an interpretation of the work of Candilis-Josic-Woods. The focus is on their main theoretical ethos and on the basis of networks being at the core of their investigation. In the field of graph theory, the study of tree networks is of particular importance and with a wide range of applications spanning from theory of networks and information theory to social sciences (Gondran and Minoux 1984: 129). Computational geometry, an independent field since the late 1970s, has extensively contributed to geometric and graph theory problems with a plethora of geometric algorithms (Kreveld et al. 2008: 1). This also led to the reinvestigation of main geometry principles allowing for a better application through computation (Gallier 2001: 4). Computational design methods now inform architectural and urban design processes and are widely used as a tool for the articulation of patterns and spatial organization.

In this context, this research examines the main principles that guided the work of Candilis-Josic-Woods and considers computational methods and algorithms 
that could be of relevance to interpreting them. Tools from graph theory are used to investigate the juxtaposition of Candilis-Josic-Woods' work with algorithms such as the Euclidean Steiner tree and the minimum spanning tree. A brief introduction of both Candilis-Josic-Woods' work principles and definitions of the main graph theory concepts used are given. This is followed by a discussion of the application of these tools in Candilis-Josic-Woods' urban design logic. A theoretical framework that would support the adoption of such systematic methods is sought. The results of a design algorithm based on the principles developed are demonstrated. Final remarks on the work of Candilis-Josic-Woods and further elaborations on infrastructure design conclude this examination.

\section{Background}

The Candilis-Josic-Woods' planning method follows the logic from stem to cluster (Woods 1960: 161) (Fig. 1). Public services and functions are gathered around main axes of pedestrian circulation and collective locations. Program and function affect the massing of commonly used structures. Additional open spaces are shared among large-scale enclosed envelopes. Along the main axes of spatial organization and in a perpendicular manner, additional housing blocks are added. On the other side of these structures, the characteristic " $\mathrm{X}$ "-shaped multi-storey buildings and parking lots complete the plan. In some of the projects, additional geometries in the form of smaller neighbourhoods would finish the urban layout. A key principle here is the location of car circulation at the circumference of the settlement. While the particular arrangement may be seen as stratified, it should be noted that the linear character of the central open space and the attachment of several dwelling units allows for cross-horizontal circulation in-between all levels at the architectural-urban design scale. Thus, the city occupant may wander from any cluster to any other one. Such a property would align
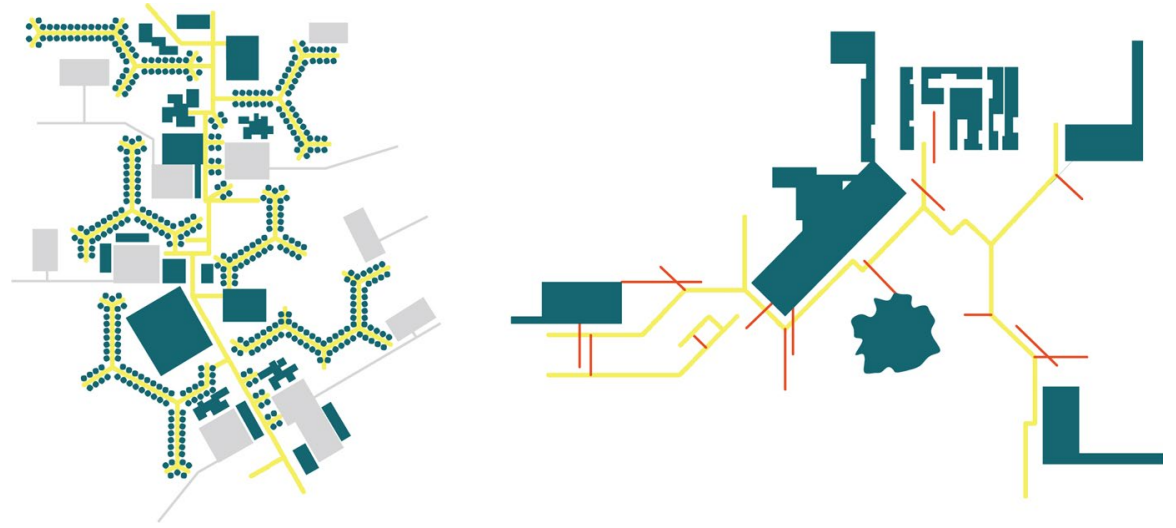

Fig. 1 Left: diagrammatic layout of the stem to cluster logic followed by Candilis-Josic-Woods. Right: public service buildings and connectivity networks with parking lots. Based on Woods (1968: 180, 194) 

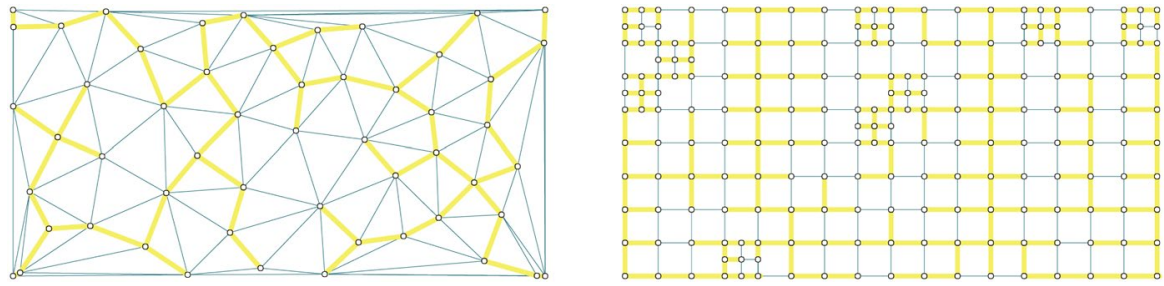

Fig. 2 A minimum spanning tree (MST) for a triangulated pattern (left) and a rectilinear grid with subdivisions (right)
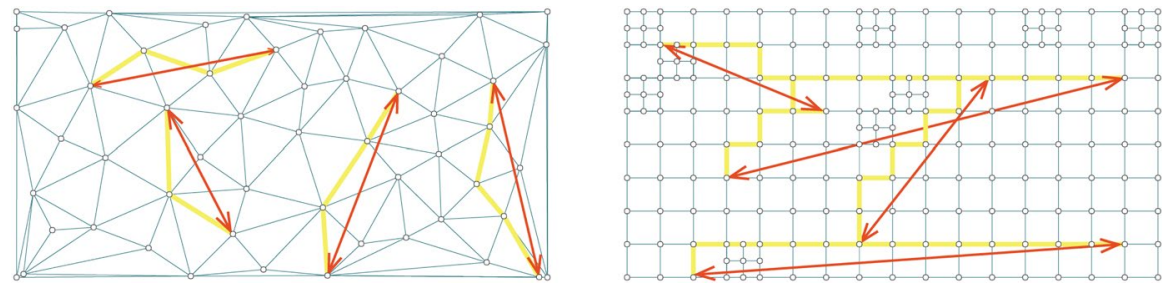

Fig. 3 Shortest paths for a triangulated pattern (left) and a rectilinear grid with subdivisions (right)

with Christopher Alexander's criticism of the hierarchical tree structure of the Modern language (Ingersoll 2006: 14).

\section{Key Geometric Concepts}

As shown in Bang and Kun-Mao (2004: 9), a minimum spanning tree (MST) of a weighted graph $G$ is a tree whose edges sum to a minimum weight and pass through all the graph nodes. Figure 2 shows the MST for a triangulated and for a grid graph configuration. A minimum spanning tree can only be applied to a subset of a graph's points.

A similar concept to the minimum spanning tree is the shortest walk tree. Given a weighted graph $G$, the shortest walk tree connects nodes such that the sum of the edge lengths is minimized (Bang and Kun-Mao 2004: 23). Figure 3 shows applications of shortest walk trees for a triangulated and rectilinear graph.

In the Steiner tree, points are grouped into two categories: points that are considered as terminals and nonterminal points. The latter group is used to facilitate the algorithm to optimize the desired path length. As a general expression from Bang and Kun-Mao (2004: 147), let $V$ be a set and $L \subset V$ where $L$ a set of terminals. The goal is to determine a subgraph connecting all the terminals. Also, in the Euclidean space, the distance $d$ between two points $\left(x_{1}, y_{1}\right)$ and $\left(x_{2}, y_{2}\right)$ of a Steiner minimal tree is given by the expression:

$$
d=\sqrt{\left(x_{1}-x_{2}\right)^{2}+\left(y_{1}-y_{2}\right)^{2}}
$$



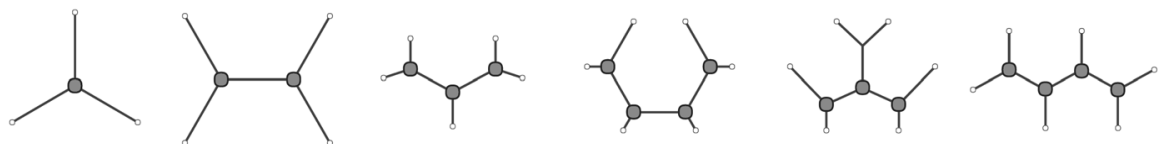

Fig. 4 Steiner tree with 3, 4, 5, 6 terminals and 1, 2, 3, 4, 3, 4 nonterminal points, respectively

A Steiner tree algorithm would generate new intermediate points, known as Steiner points, the count of which is determined by the desired length of the path. This allows for multiple solutions for a given number of points. Figure 4 shows Steiner trees with different numbers of terminal and nonterminal points.

\section{Patterns of Organization in the Work of Candilis-Josic-Woods}

\section{Mat-Building Configuration}

Figure 5 is a simplified version of a plan of the Free University in Berlin, showing how a combination of a Euclidean Steiner logic and a shortest walk tree algorithm could be used to configure circulation in the building. Spaces are paired based on proximity, then a Euclidean Steiner diagram is created. A shortest walk tree algorithm is used to connect the endpoints of the Euclidean Steiner diagram by following the rectilinear grid. In that way, a network of connectivities within the grid is established. Corners-nodes are therefore increased to multiply the moments of social interaction. Of course, the concept of the mat-building, as well as a realized paradigm, the Free University in Berlin, are both of key importance in the history of Team X and the work of Candilis-Josic-Woods has been extensively discussed in the context of the stem to cluster concept (Smithson 1974; Feld 1999). However, we can still suggest a principle of spatial co-relations following the approach of this paper. Because the primary investigation in this research is of circulation, program requirements and layouts of open and enclosed spaces are excluded. This results in a level of random organization in the spaces analysed.
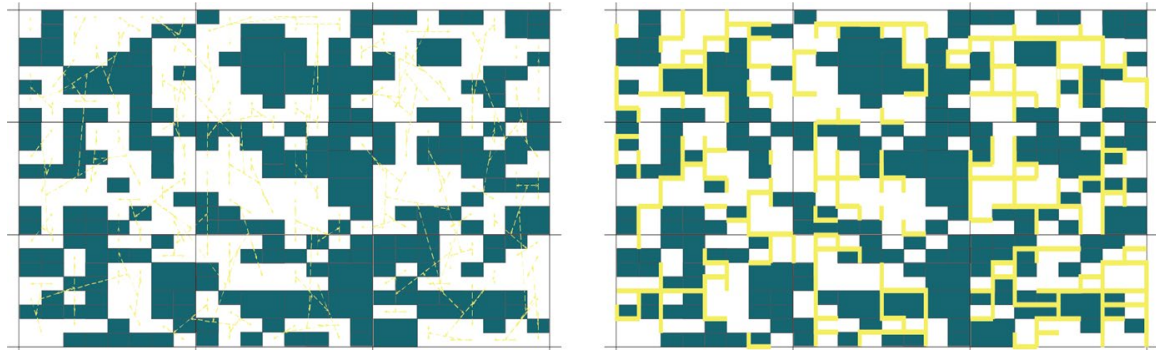

Fig. 5 Left: random rectilinear grid arrangement of spaces with desired connectivities (yellow) in the form of Steiner trees. Right: a transformation of desired Steiner trees to shortest walks onto the rectilinear grid 

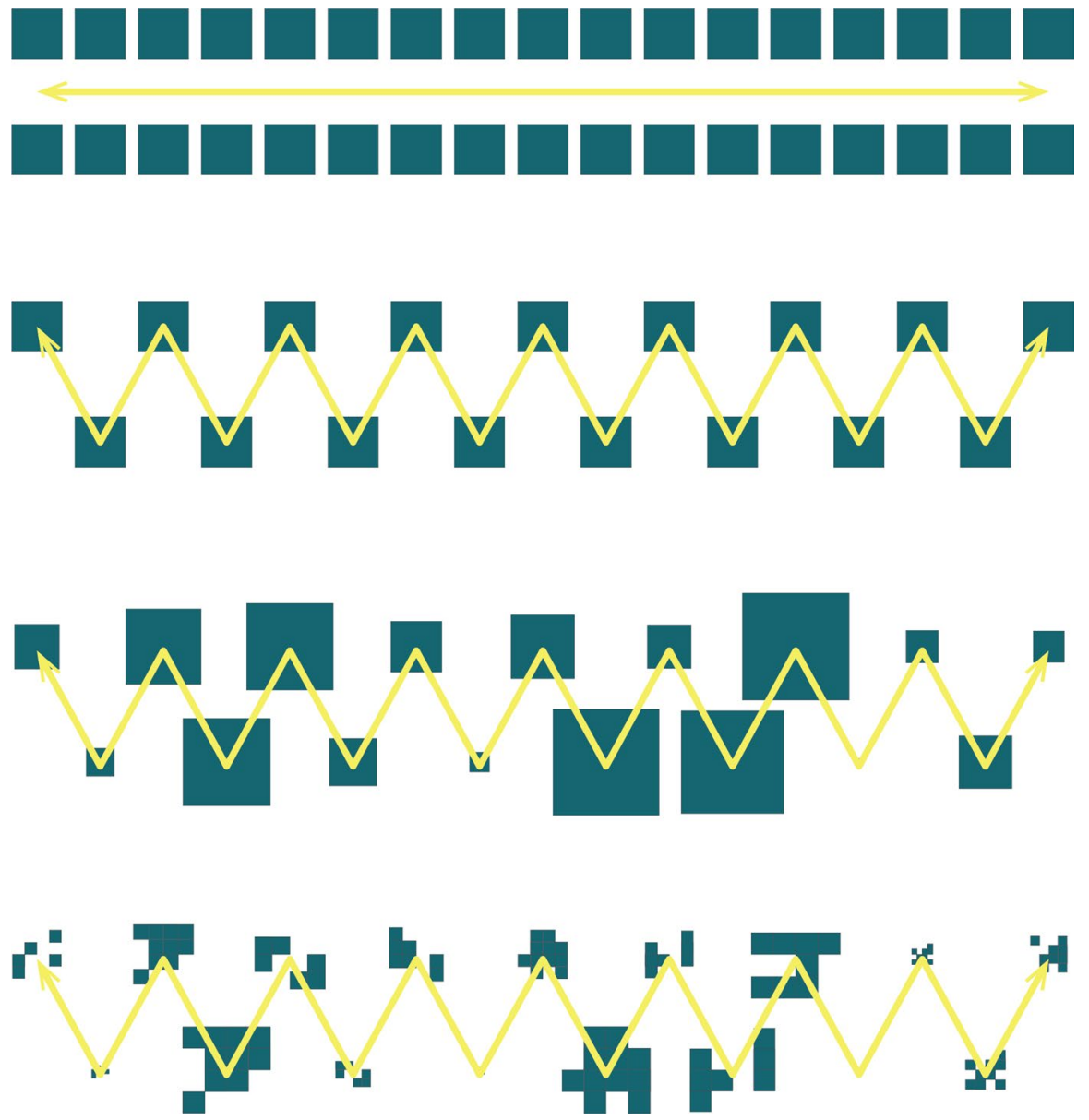

Fig. 6 Circulation logic for public service buildings in the work of Candilis-Josic-Woods. A crinkled journey is preferred over a linear one. Multiple stops allow for more social interaction and program relations. The logic of the buildings further generates internal paths

\section{Public Space and Service Buildings}

Shifting to urban space, for Candilis-Josic-Woods, the arrangement of public buildings follows the same approach. Pedestrian circulation aims at maximizing human interaction. Figure 6 shows a suggested strategy within the open space. Instead of creating a linear path, the traveller is encouraged to have multiple stops. Such an arrangement would conform with Alexander Tzonis' (Avermaete 2005: 83) note on the importance of the aspect of the commonplace, as he would argue that movement is not considered a "plastic" or "formal" action but it is rather "flexible" and carried on by "ordinary people, facing problems of everyday life". At the same time, the internal organization of public function-related buildings may follow the mat-like organization. Thus, a Euclidean Steiner tree across the public 
buildings is further expanded to a minimum spanning tree within the structures. Candilis-Josic-Woods would argue that the purpose of the street and its structures is to gather the inhabitants around the main activities of the settlement. As Tom Avermaete (2005: 206) argues, clearly, there is a reference to Henri Lefebvre and the significance of the street, an entity that must be regained since it consists of a place that unlocks the potential of the city's activities. Stan Allen (2009: 198) discusses two possible analogies when investigating the origins of the city, one of them being the corral, the other the souk. The corral refers to a strategy of partitioning an urban settlement based on property and the souk, as a marketplace, is a place of gathering and a locus of exchanging artifacts and ideas. The Candilis-Josic-Woods' urban planning and design philosophy would endorse the latter approach, as it envisions space as a canvas for human activity and interaction.

A key concept to the Candilis-Josic-Woods' strategy is the potential of intersecting routes when pedestrians are circulating. A route from point $A$ to point $B$ is considered an opportunity to engage in more events and a possibility for intermediate stops before the destination. For that to take place, car circulation is pushed outside the settlement through rings. Connection of these rings with the other areas of the plan may only take the form of points. All these decisions result in non-linear layouts of organization in favour of network arrangements that manifest routes of pedestrian and automobile passages. Candilis-Josic-Woods' concerns were based on emphasizing pedestrian circulation as opposed to the use of the car, as well as the different scale of urban interventions. As Kenneth Frampton (1980: 277) commented, their work aimed at putting the automobile "in its place" and treating the city as "both functional and open".

\section{The Dwelling Block as a Manifestation of Intermediate Nodes}

The "X"-shaped structure is a characteristic architectural form in the work of Candilis-Josic-Woods. Its typical location on settlement layouts is between buildings referring to public use on one end and parking lots on the other end. Interestingly, this specific structure presents as a Euclidean Steiner tree. Terminal points consist of the two pair-points on the ends. The tree is then constructed by generating the intermediate Steiner points. In this case, Steiner points become connection hubs within the building structure that can provide locations for vertical circulation. Finally, the internal arrangement of the apartments can follow a logic similar to the one seen in the public buildings (Fig. 7).

Steiner points in the diagram represent the moments of intersection paths of the inhabitants in their daily life. In this case, the transformation of a Steiner diagram into an architectural object is of crucial importance. It admits that the architectural form may emerge from circulation networks themselves, beyond a mere construction of program. A path designed by the architect-planner may redirect itself to facilitate the movement based on a combination of the paths of all the residents. Therefore, the characteristic dwelling block in the work of Candilis-Josic-Woods manifests the strategy of the architects by itself, and that would be the construction of an open-ended process of generating key Steiner 

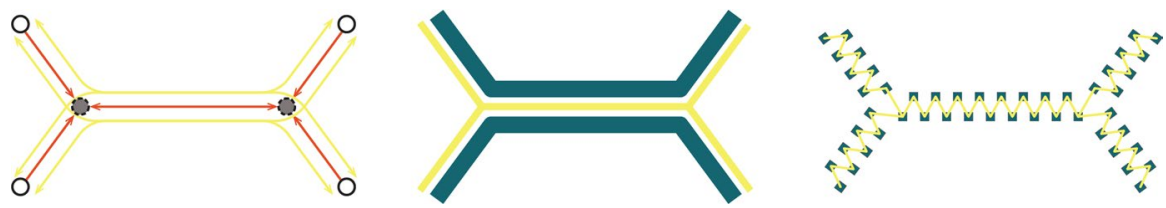

Fig. 7 The dwelling block and its formal resemblance to a Euclidean Steiner diagram. Intermediate nodes aim at minimizing the paths between endpoints but at the same time they maximize social interaction. The internal logic of the apartment arrangement can be a subsystem of crinkled circulation

points that allow for social interaction. To use Alison Smithson's (1974: 580) description, "the parts of a system take their identity from the system". Endpoints are only necessary for addressing the boundary question and they can still connect to other networks. The intermediate state of circulation remains open to interpretation and its logic may deliver multiple solutions. This is the moment the concrete language of modern architecture adapts to the social aspects of everyday life.

\section{Generic Layout of Connectivity Networks}

In planning and urban design arrangements, all routes discussed so far can connect to a network covering entire settlements. Figure 8 illustrates these layouts combined. The main pedestrian arteries connect to building blocks that lead to automobile parking spaces. Candilis would argue that connections should always be made through points, to eliminate having parallel axes of circulation (Avermaete 2005: 251). Non-linear building-to-building connections generate interactions around public service facilities. Interactions on the street, the "locus of activities" (Avermaete 2005: 258), follow the internal logic of spatial arrangement inside the large-scale structures. Connections of the dwelling blocks to the street are smaller branches of circulation, therefore, the hubs with their vertical motion become of major importance. Car access to the settlement is limited to the circumference that only connects to the residential buildings through points.

The linear arrangement provided here can be applicable to different geometries or, as a section of a larger Steiner diagram. This seems to be the case in most of Candilis-Josic-Woods' projects (Fig. 8). Therefore, it should be argued that making initial terminal points parking lots gives the original input to a Steiner diagram that generates a settlement's main street. This street then subdivides the given area into subregions that develop further Steiner diagrams recursively. Furthermore, the syntax allows for additional expansion of the settlement with any addition of external terminal points. This results in activating several different streets simultaneously, therefore allowing for a time-based reconfiguration of space (Zavoleas, 2013: 171). Also, Avermaete notes Candilis' views on expansion as opposed to a centric-oriented town (Avermaete 2005: 263). 


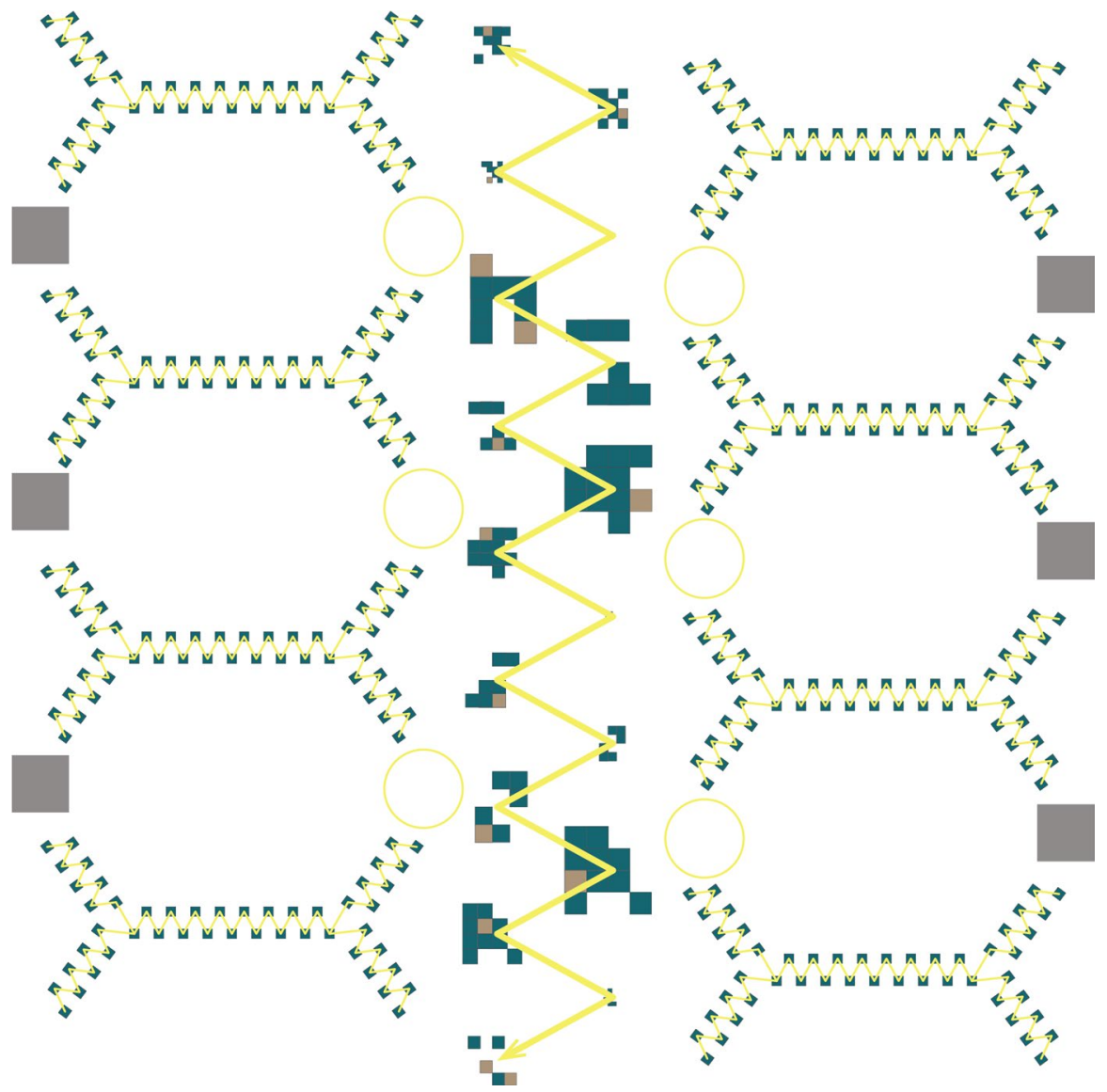

Fig. 8 Combination of systems of pedestrian circulation. Nodal connections applied between the systems to eliminate parallel circulations

\section{Pattern Design Algorithms Based on the Work of Candilis-Josic- Woods}

As diagrams remain of key importance for typology and syntax experimentation (Lee et al. 2010: 2), a diagrammatic implementation of the prism developed here will contribute to discussion in architectural research. Such a generic exploration can introduce applicable models in today's congested cities due to their intertwined networks. Since the function of an urban environment currently lies in the efficient transmission of elements (products, communication, services, etc.) through gateways and channel systems, the optimization of these arrangements is crucial. While such cross-hierarchical organizations of juxtaposed structures require effective operation, real-time reflections on evolving conditions are essential (Mitchell 2013: 382). A tangible and articulated dimension of these entities is a key question of architectural importance. For 
this study, the Steiner point construction is seen as a pure manifestation of a response to urban circumstances unfolding over time. Terminal points guide the creation of in-between hubs. What then follows is the enveloping of the network through the various architectural and urban design typologies developed by Candilis-Josic-Woods. This open-ended process suggests an adaptive and incomplete architectural environment, a flexibility clearly questioning the strict Modernist approach to composition (Zavoleas and Taylor 2019: 10). Essentially, the 2D layout of Candilis-Josic-Woods' plan is transposed to a 3D system depicting the complexity of today's networks. Furthermore, as Allen points out (2009: 205), the establishment of relationships between connectivity and emergence can be also implemented in the integration of the urban settlement with the landscape, thus the orchestration of the strategy shifts the discussion to landscape urbanism.

Examples of developing applications of this type are shown in Figs. 9, 10 and 11. Potential arrangements are based on a Euclidean Steiner tree population algorithm. Beginning with a set of nodes that cluster into pairs, proximity parameters generate Steiner points that are used as input to connect to a neighbouring pair and its Steiner point respectively. On a second level, smaller regions generated around the initial stems are populated to recursively repeat the process. A computational model in Rhinoceros 3D and Grasshopper as well as relaxation methods with Kangaroo were used. The outcome effectively lacks the adoption of strict geometric angles relevant to Candilis-Josic-Woods' vocabulary. Finally, the Candilis-Josic-Woods' stem to cluster logic can be explored in $3 \mathrm{D}$ to study intermediate locations in different types of networks. This aspect of emergence is of importance in the field of computational design, as formal arrangements can appear and inform spatial organization. Implementations here also include rectilinear path construction methods.

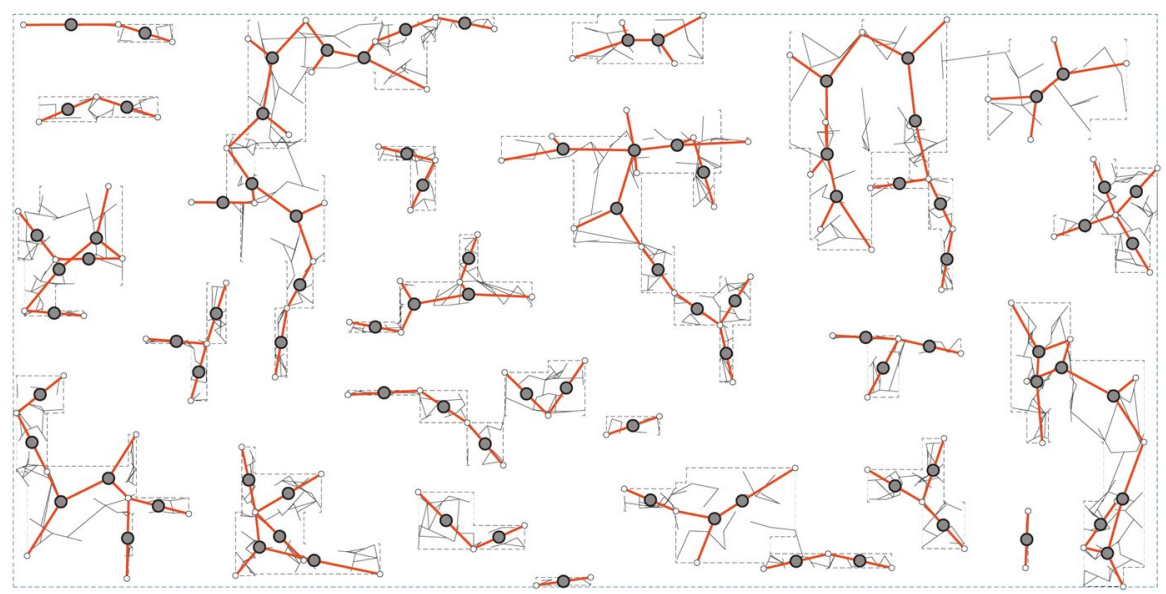

Fig. 9 2D structures generated using a Euclidean Steiner tree-based algorithm. Neighbouring pairs based on proximity define terminal points for the Steiner trees. The process is then repeated for smaller clusters around the created stems 


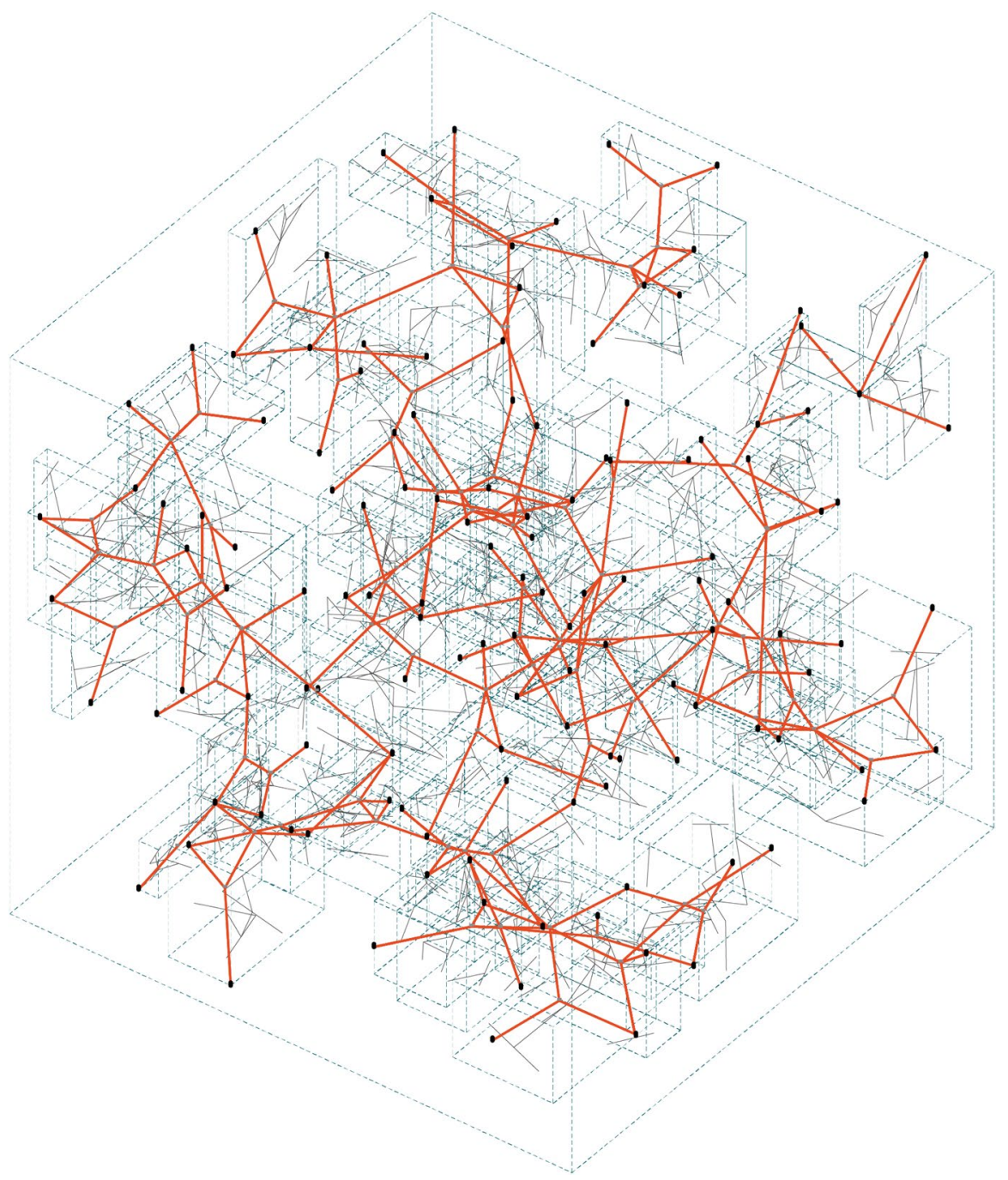

Fig. 10 3D structures generated using a Euclidean Steiner tree-based algorithm. Neighbouring pairs based on proximity define terminal points for the Steiner trees. The process is then repeated for smaller clusters around the created stems

\section{Conclusion}

This paper introduced a systematic and algorithmic approach to the study of the work of Candilis-Josic-Woods. An outline of their main planning and urban design principles was given. Then, tools from the field of graph theory were introduced, the minimum spanning tree, the shortest walk tree, and the Steiner tree. A projection of these mathematical concepts was undertaken on diagrams of the work of Candilis-Josic-Woods. An exploration of the theoretical background in defence 


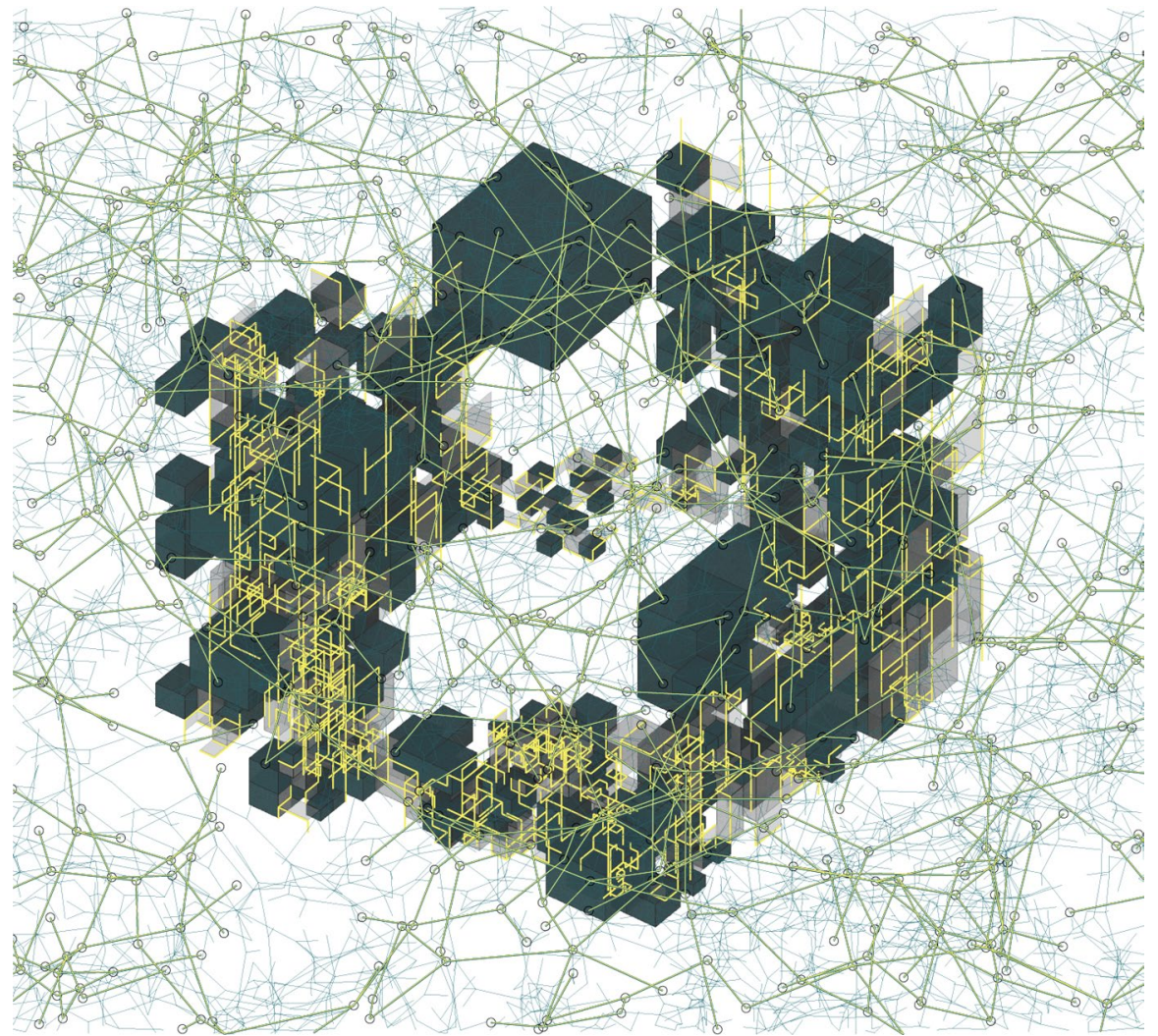

Fig. 11 A Euclidean Steiner tree-based algorithm is superimposed over a 3D mat-building configuration. Neighbouring pairs based on proximity define terminal points for the Steiner trees. For the mat-structure, rectilinear Steiner trees are generated. The logic pervades the different configuration typologies

of the use of distance-based and proximity-based geometric methods in the work of the architects was made. Furthermore, design examples of the development of a global Euclidean Steiner tree generation algorithm were shown. The architectural and urban planning vocabulary used by Candilis-Josic-Woods may be regarded as restricted and sometimes controversial, however their methodology is systematic. It consists of a syntax that places human needs and their interactions as the creation of place at the core of its strategy. Steiner points prove the intent to allow the system to evolve via an open-ended process that simulates the development of the urban settlement. These intermediate points assist in formalizing the building and are a part of the articulation of the street layout. At the same time, Steiner points can be seen as activation locations in public space.

Historically, Candilis-Josic-Woods' urban design and architectural vocabulary was one of the first examples of adopting modern abstraction, by criticizing the strict austerity of a monothematic language. By expanding to include real aspects of city life, the architects established a taxonomy of building typologies with 
given formal characteristics aiming at delivering a spatial differentiation of the built environment. However, these typologies are the result of the same planning principles that amalgamate in different architectural scales. The mat-building refers to the broader public, the housing blocks seize the circulation in pure form, and the clusters generate local neighbourhoods. Structures are designed and articulated in a way that facilitates pedestrian circulation and energizes the connection nodes.

A response to Allen's (1997) discussion of infrastructural urbanism can be framed with the example of Candilis-Josic-Woods' work and the mathematical logic presented in this paper. Allen would critique the static and efficiency-based strategy ruling the design of infrastructure. Given the infrastructural nature of the work of Candilis-Josic-Woods, the Steiner tree-based logic elaborated here presents a dynamic and open-ended procedure that can be used for the design of such systems, as their configuration is re-informed each time the process is repeated with different inputs. Therefore, the social aspect of interaction can indeed be considered for the formation of infrastructure systems. In a global setting of settlements functioning among physical and aethereal networks, the emergence of in-between hubs that manifest as points of path intersections celebrates the affirmation of the dynamic character of cities. Graph theory tools applied on urban design and planning introduce a powerful and cross-disciplinary thesaurus in the study of complex network settings in urban environments and offer potential in addressing the social aspects of city planning and design.

Acknowledgements The author would like to thank the editors for their comments, but mainly for giving him the opportunity to revisit the work of Candilis-Josic-Woods, a topic he had briefly explored with Ciro Najle and Pablo Barria Urenda at the GSD during his first steps in computational design.

All figures are by the author.

Open Access This article is licensed under a Creative Commons Attribution 4.0 International License, which permits use, sharing, adaptation, distribution and reproduction in any medium or format, as long as you give appropriate credit to the original author(s) and the source, provide a link to the Creative Commons licence, and indicate if changes were made. The images or other third party material in this article are included in the article's Creative Commons licence, unless indicated otherwise in a credit line to the material. If material is not included in the article's Creative Commons licence and your intended use is not permitted by statutory regulation or exceeds the permitted use, you will need to obtain permission directly from the copyright holder. To view a copy of this licence, visit http://creativeco mmons.org/licenses/by/4.0/.

\section{References}

Allen, Stan. 1997. Infrastructural Urbanism. Scroope Cambridge Architectural Journal 9: 48-57.

Allen, Stan. 2009. The Thick 2-D: Mat-Building in the Contemporary City. In Practice: Architecture Technique + Representation. Stan Allen, ed. 192-215. Abbingdon: Routledge.

Avermaete, Tom. 2005. Another Modern: the Post-war Architecture and Urbanism of Candilis-JosicWoods. Rotterdam: NAi.

Busquets, Juan and Felipe Correa. 2006. Cities X lines: A new lens for the urbanisitic project=ciudades $X$ formas: Una nueva mirada hacia el proyecto urbanístico. Cambridge, MA: Harvard University Graduate School of Design. 
Feld, Gabriel. 1999. Free University, Berlin: Candilis, Josic, Woods, Schiedhelm. London: Architectural Association.

Frampton, Kenneth. 1980. Modern architecture: a Critical History. London: Thames and Hudson.

Frampton, Kenneth and Ashley Simone. 2015. A Genealogy of Modern Architecture: Comparative Critical Analysis of Built Form. Zurich: Lars Müller Publishers.

Gallier, Jean H. 2001. Geometric Methods and Applications: for Computer Science and Engineering. New York, N.Y.: Springer.

Gondran, Michel and Michel Minoux. 1984. Graphs and algorithms. Chichester: Wiley.

Ingersoll, Richard. 2006. Sprawltown: Looking for the City on Its Edges. New York: Princeton Architectural Press.

Kreveld, Marc van, Mark de Berg and Otfried Cheong. 2008. Computational geometry: algorithms and applications. Berlin: Springer-Verlag.

Lee, Christopher C. M., Gupta Kapil and Serie Architects. 2010. Working in Series. London: Architectural Association Publications.

Mitchell, William J. 2013. Sustainable Urban Mobility through Light Electric Vehicles. In: Ecological Urbanism. Mohsen Mostafavi and Gareth Doherty eds. 382-397. Zurich: Lars Müller Publishers.

Mumford, Eric Paul. 2000. The CIAM discourse on urbanism, 1928-1960. Cambridge, Mass.: MIT Press.

Mumford, Eric. 2009. The Emergence of Urban Design in the Breakup of CIAM. In: Urban Design. Alex Krieger and William S Saunders, eds. 15-37. Minneapolis, Minnesota: University of Minnesota Press.

Risselada, Max. and Dirk van den Heuvel. 2005. Team 10, 1953-1981: In Search of a Utopia of the Present. Rotterdam: NAI.

Smithson, Alison, 1974. Mat-building: Mainstream Architecture as it has Developed towards the MatBuilding. Architectural Design 9: 573-590.

Smithson, Alison. 1991. Team 10 meetings: 1953-1984. Delft, the Netherlands: Publikatieburo Bouwkunde.

Vidler, Anthony. 2004. Type, Diagram. The City: Revisiting Paradigms of Design from Rossi to Koolhaas. In: The European City: Architectural Interventions and Transformations. EAAE Transactions on Architectural Education; No.25. Duin Claessens, Francois Claessens and L. Van Duin eds. 26-37. Delft, The Netherlands: DUP Science.

Woods, Shadrach. 1960. Stem. Architectural Design 5: 161-162.

Woods, Shadrach. 1968. Candilis, Josic, Woods: a Decade of Architecture and Urban Design. London: Tiranti.

Wu, Bang Ye and Kun-Mao Chao. 2004. Spanning Trees and Optimization Problems. Boca Raton, FL: Chapman \& Hall/CRC.

Zavoleas, Yannis. 2013. Machine and Network as Structural Models in Architecture. Athens: Futura.

Zavoleas, Yannis and Mark Taylor. 2019. From Cartesian to Topological Geometry: Challenging Flatness in Architecture. Nexus Network Journal 21: 5-18. https://doi.org/10.1007/s00004-018-0414-8

Publisher's Note Springer Nature remains neutral with regard to jurisdictional claims in published maps and institutional affiliations.

Georgios-Spyridon Athanasopoulos holds a Bachelor of Architecture from Technical University of Crete School of Architecture and a Master of Architecture in Urban Design from Harvard Graduate School of Design. He has worked as an urban designer and architect in Greece, Massachusetts, and Germany. As a designer and researcher his work crosses the boundaries of computational design, topology, and architectural technology. He is currently a $\mathrm{PhD}$ candidate at the Engineering Department of the University of Cambridge where he is ongoing research focuses on the development of innovative geometric and computational methods to facilitate the collaboration between structural engineers and designers. 